\title{
Design of an Aircraft Wing Structure for Static\& Fatigue Life Prediction
}

\author{
Raju T, Kishore Kumar K, Jawahar M
}

\begin{abstract}
A wing is a type of blade with a ground that produces streamlined power for flight or strain via the surroundings, (o r) through every other vaporous or fluid liquid. In that potential, wings have an airfoil form, a streamlined pass-sectional form handing over carry. A wing's streamlined $e$ satisfactory is communicated as its increase-to-drag percentage. The increase a wing creates at a given velocity and approach may be one to 2 units of quantity extra fantastic than the absolute delay the wing. A excessive convey-to-drag percentage calls for an altogether littler push to pressure the wings through the air at true sufficient raise. The conditions for the air deliver wing are excessive firmness, high extremely good, high durability and occasional weight.

In shape and constrained issue research of flying system wing is planned and confirmed in three-d displaying programming CATIA. The wing is altered with the aid of manner of 3 noteworthy arrangement structure geometries figuring out with decrease share are rectangular, trapezoidal and delta shape. to be able to assemble the great of the wing Trapezoidal maximum ideal for out of 3 shapes. So Trapezoidal form air uniqueness wing is applied in those art work. in this the NACA-4 digit affiliation is carried out for making wing skeleton form and later we made showing, Fatigue and auxiliary research on wing Skelton structure by way of using ANSYS paintings BENCH. The substances applied for air deliver wings are for the maximum factor steel mixtures. on this postulation, the substances are supplanted via composite materials S2 Glass and Kevlar 40 nine.

Static examination is completed to determine the distortion ,stresses and lines added by means of making use of loads. weak spot exam to appraise the existence, harm and well being component of the wing. Modular examination is completed on the air deliver wing to decide the misshapenings and frequencies, worry because of frequencies. investigation is completed in ANSYS.
\end{abstract}

Document phrases:- Aero dynamic electricity, bring-to-drag share, 3-D demonstrating programming CATIA, metal alloys,S2 Glass, Kelvar49, ANSYS.

\section{INTRODUCTION}

A consistent-wing craft is Air craft, like a plane. a fixed wing craft is capable of flight exploitation wings via generating improve due to the car's in advance air space and consequently the form of the wings. fixed-wing craft vicinity unit clearly specific from rotary-wing craft, inside which the wings kind a rotor mounted on a spinning shaft, inside which

the wings flap within the identical manner to a chook. Aero

Revised Version Manuscript Received on 10 September, 2019.

Raju T, Assistant Professor, Jayamukhi Institute of Technological Sciences, Telangana, India.(Email: thoutamraju1992@gmail.com)

Kishore Kumar K, Assistant Professor, Kakatiya Institute of Technological \& Sciences, Telangana, India. (Email: kishore.kits@gmail.com)

Jawahar M, Associate Professor, Jayamukhi Institute of Technological Sciences, Telangana, India. (Email: jawahar.mamidala123@gmail.com) plane steady-wing craft, further to free-flying gliders of various types and certain kites, will use shifting air to apprehend top. Steam-powered consistent-wing craft profits in advance thrust from AN engine (aero planes) that embody steam-powered paragliders, steam-powered hunch gliders and some carry cars. The wings of a set-wing craft place unit won't be inflexible. Samples of fixed wing craft location unit kites, draw close-gliders, variable-sweep wing craft and aero planes exploitation wing-warping. most fixed-wing craft place unit flown through the use of a pilot on board the craft, however a number of the patterns vicinity unit controlled thru an foreign places or by laptop systems.

\section{II.AIRFOIL TERMINOLOGY AND DEFINITIONS.}

\subsection{Airfoil}

An airfoil shape is defined by several parameters, which are shown in the figure below.

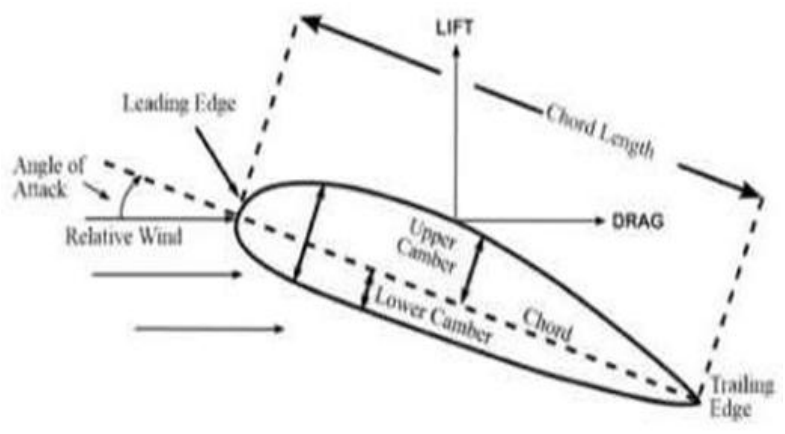

Figure1: Airfoil Geometry

Chord Line: immediately line drawn from the precept element to the trailing facet

Chord duration (c): duration of the concord line

suggest Camber Line: Curved line from the number one issue to the trailing element, which is equidistant most of the higher and decrease surfaces of the airfoil

maximum (or certainly) Camber: maximum separation between the concord line and the imply camber line.

\subsection{NACA four-DIGIT series.}

don't forget the airfoil NACA 2412. the foremost digit offers greatest camber in degree of harmony, the subsequent digit offers in tenth of a harmony in which the most intense camber happens, and the remaining digits deliver the

\section{Published By:}


maximum excessive thickness in charge concord.

\section{CLOTH SELECTION}

on this task substances are applied, they're S2 glass and kelvar49, the two materials have some characteristics which might be most appropriate for wing shape.

\subsection{S2 Glass material.}

Created with a extra expanded quantity of silica than stylish glass fiber items, S-2 glass strands offer a definitive physical properties which encompass excessive tensiles and compressive fantastic, excessive temperature opposition, and advanced impact obstruction.

\subsection{Kelvar49 fabric.}

Kevlar is applied for elastic assist as in defensive layer coats. Kevlar-forty nine fiber has a tension nearly same with that of carbon fiber, a modulus among the ones of glass and carbon filaments and a lower thickness than both.

\section{3 material residences}

The cloth houses utilized throughout this investigation are seemed under table 1.

Table 1: Material Properties.

\begin{tabular}{|c|c|c|}
\hline Material & S2 Glass & Kelvar49 \\
\hline Young's modulus(Mpa) & 89000 & 80000 \\
\hline Poisson's ratio & 0.23 & 0.21 \\
\hline Density $\left(\mathrm{Kg} / \mathrm{m}^{\mathbf{3}}\right)$ & 2490 & 2550 \\
\hline
\end{tabular}

\section{IV.PROBLEM SPECIFICATION.}

on this mission we discover which material is maximum appropriate for the air deliver wing (S2 Glass or Kelvar49). For wing Skelton shape we use NACA 2412 co-ordinates. We observe the restrict conditions on the wing. We fixed one part of the association and we are capable of look at the burden $30 \mathrm{kPa}$ on the very quality point of wing and the gravity along Y-course. we are intrigued to discover the Static auxiliary evaluation parameters like deformation( $\mathrm{mm})$, strain(MPa), strain. In Fatigue evaluation decided parameters like lifestyles, harm, safety component notably Modal exam parameters like general twisting, recurrence. searching at of the two materials is finished and the nice fabric is picked for the wing configuration as in step with the most suitable Structural, Fatigue and Modal analysis parameters.

\section{V.FINITE DETAIL EVALUATION.}

FEA has modified into a solution for the errand of foreseeing unhappiness because of difficult to recognize issues through demonstrating difficulty zones in a cloth and permitting originators to peer most people of the hypothetical troubles inner. nearly speakme, a restricted issue research more frequently than no longer incorporates of 3 leader advances:

1. Pre-managing.

2. evaluation.

3. submit-managing.

\section{WING DESIGN PROCEDURE}

The degree of increase created with the aid of way of an airfoil is primarily based on severa variables. they're approach, the raise gadgets implemented (like folds), the thickness of air, the vicinity of wing, the country of wing, the speed at which the wing is voyaging. some factors influencing wing length they're journey drag, slow down speed, take-off and touchdown separation. The initial step is to get the airfoil shape inside the Ansys workbench. As we're considering that wing is deliberate with only a unmarried airfoil for the duration of, it should be downsized because it should be to get the specified country of a wing profile. As said before, for wing Skelton shape we use NACA 2412 co-ordinates.

\section{1 bodily model OF WING.}

The bodily form proven on this art work is an air supply wing of airfoil Tapered pass region NACA 2412 affiliation. Its measurements are that of an exam subsonic air deliver wing. The Wing variety is nine. $144 \mathrm{~m}$,Wing harmony duration is $1.524 \mathrm{~m}$, Rib thickness is four. $572 \mathrm{~mm}$,Spar thickness $3.0 \mathrm{~mm}$, and skin thickness is $1 \mathrm{~mm}$.it's miles crafted from a S2 Glass(1st case) and Kelvar49 (2nd case) structure.

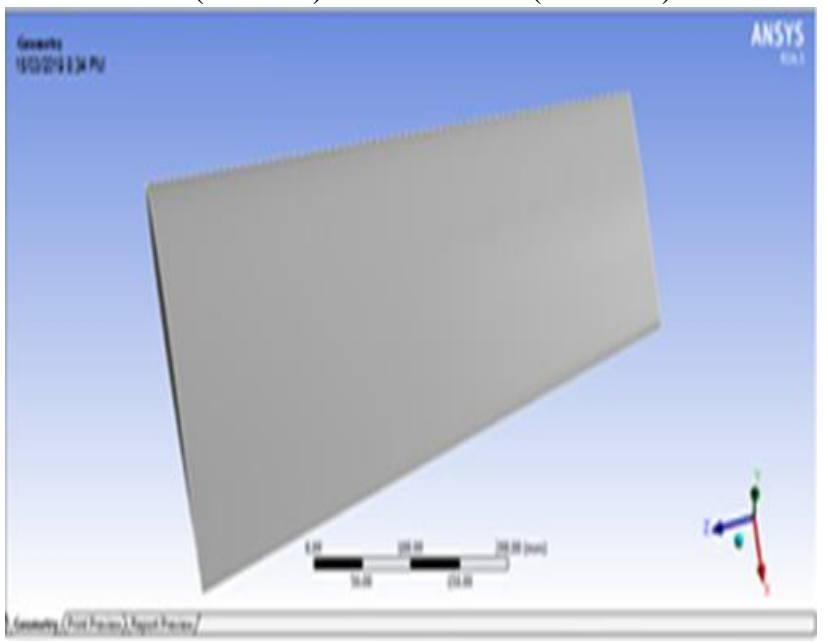

Figure2: Physical Model Tapered Aircraft Wing.

\section{VII.RESULTS AND DISCUSSIONS.}

In static auxiliary examination we are intrigued to find out the Static primary analysis parameters like deformation $(\mathrm{mm})$, pressure( $\mathrm{MPa})$, pressure, and additionally Fatigue Structural investigation we're find out the Fatigue analysis parameters like lifestyles, harm, protection factor. Modular exam is executed on the aircraft wing to determine the misshapenings and frequencies, fear due to frequencies. For the first case we're able to do the fundamental examination of S2 Glass\& Kelvar49. For the second case we are able to do the Fatigue exam of S2 Glass and Kelvar49. For the 0.33 case we are able to do the Modal investigation of S2 Glass and Kelvar49. 


\subsection{Structural Analysis Of S2 Glass \& Kelvar49.}

7.1.1. Structural Analysis With S2glass.

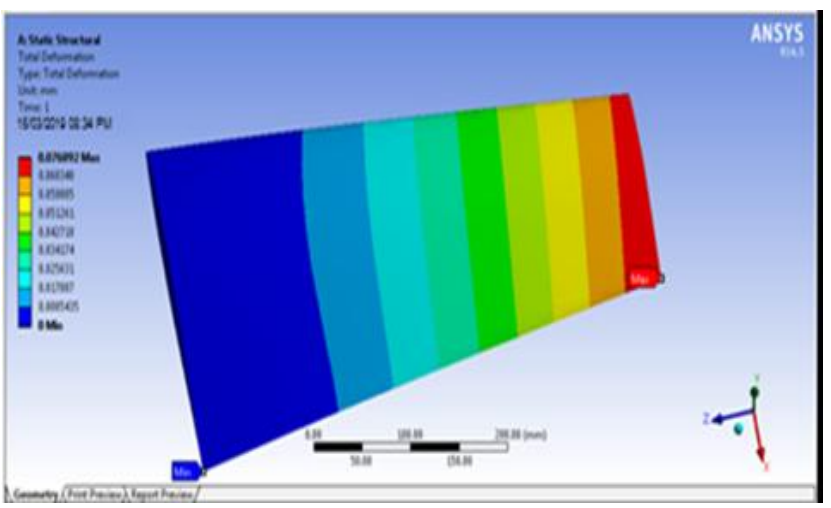

parent three: total deformation value of S2 GLASS at pressure load $30 \mathrm{kPa}$, it indicates the max cost of overall Deformation is zero. $057516 \mathrm{~mm}$.

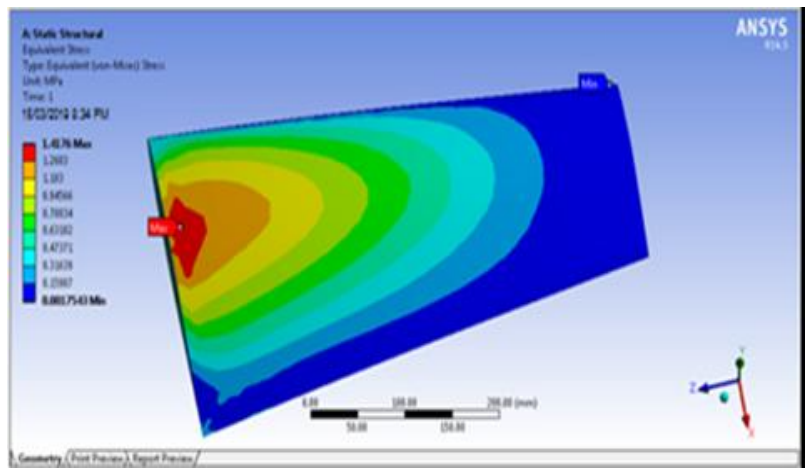

Figure 4:Stress value of S2 GLASS at pressure load $30 \mathrm{kPa}$, it shows the max value of stress is $1.4062 \mathrm{MPa}$.

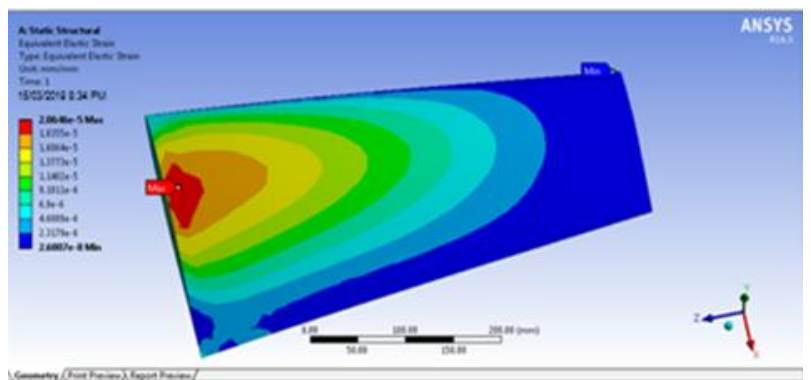

Figure 5:Strain value of S2 GLASS at pressure load $30 \mathrm{kPa}$, it shows the max value of strain is $1.5154 \mathrm{e}-5$.

\subsubsection{STRUCTURAL ANALYSIS WITH KELVAR 49}

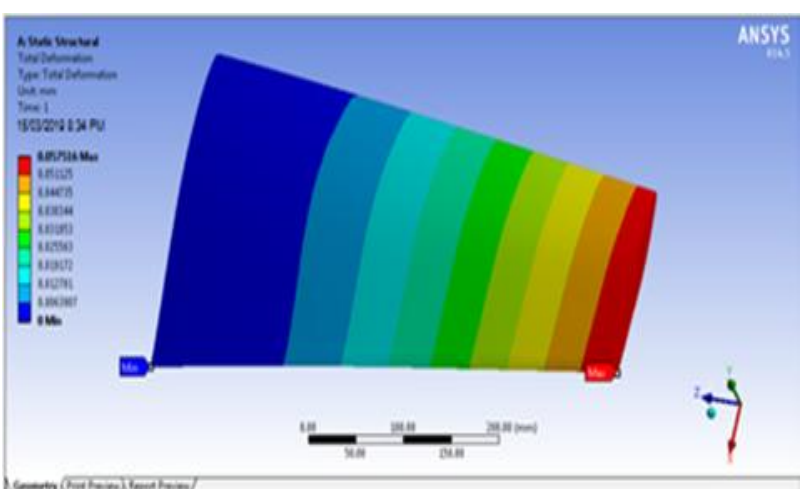

Figure 6: Total deformation value of KELVAR49 at pressure load 30kPa, it shows the max value of Total Deformation is $0.040038 \mathrm{~mm}$.

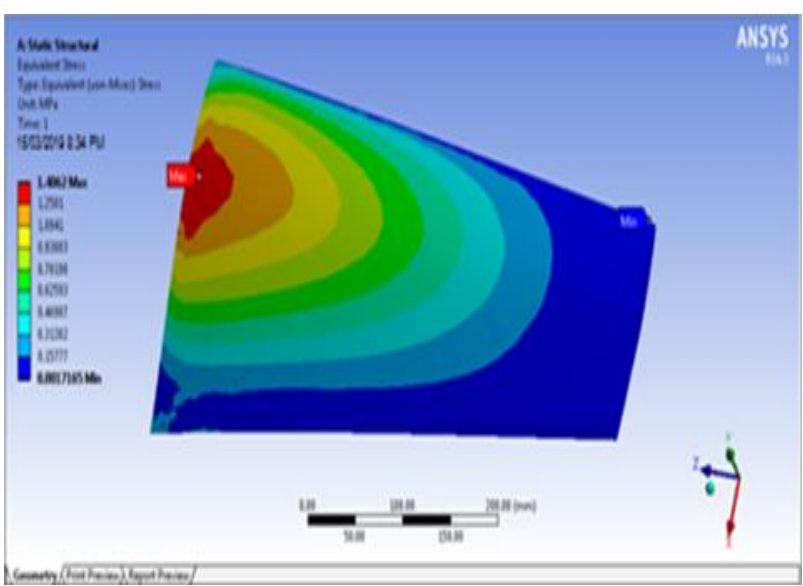

Figure 7:Stress value of KELVAR49 at pressure load $30 \mathrm{kPa}$, it shows the max value of stress is $1.4369 \mathrm{MPa}$.

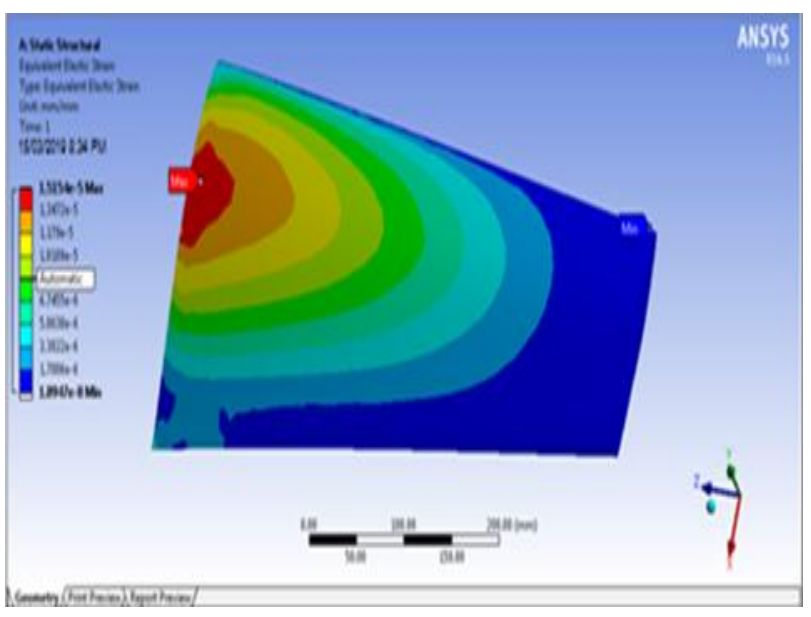

Figure 8:Strain value of KELVAR49 at pressure load $30 \mathrm{kPa}$, it shows the max value of strain is 1.1007e-5.

\subsection{Structural Analysis Result Comparision}

The Table 2 shows the values of deformation, stress and Strain with S2 GLASS and KELVAR49.

\begin{tabular}{|c|c|c|}
\hline MATERIAL & S2 GLASS & KELVAR49 \\
\hline Deformation(mm) & 0.057516 & 0.040035 \\
\hline Stress $(\mathrm{MPa})$ & 1.4062 & 1.4369 \\
\hline Strain & $1.5154 \mathrm{e}-5$ & $1.1007 \mathrm{e}-5$ \\
\hline
\end{tabular}

\subsection{Fatigue Analysis Of S2 Glass \& Kelvar49.}

\subsubsection{Fatigue Analysis With S2-Glass.}

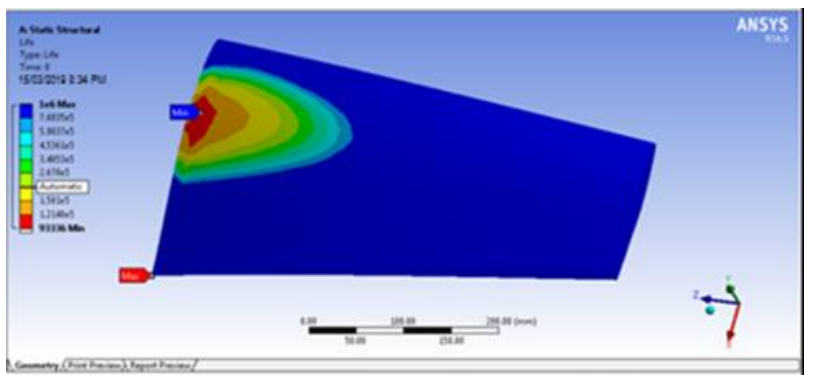

Figure 9: Life of S2 GLASS at pressure load 30kPa, it shows the max value of Life is $1 \times e 6$.

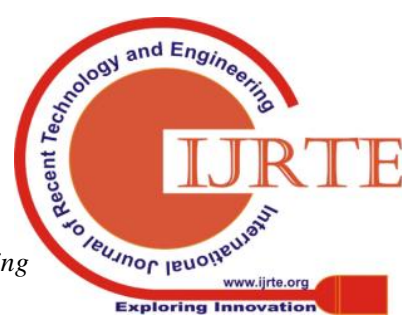




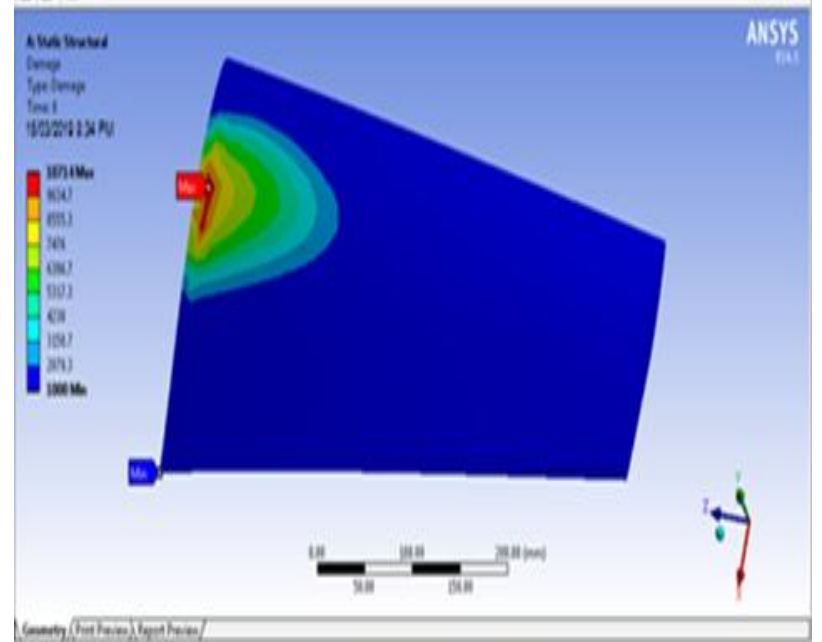

Figure 10: Damage of S2 GLASS at pressure load $30 \mathrm{kPa}$, it shows the max value of Damage is 10714 .

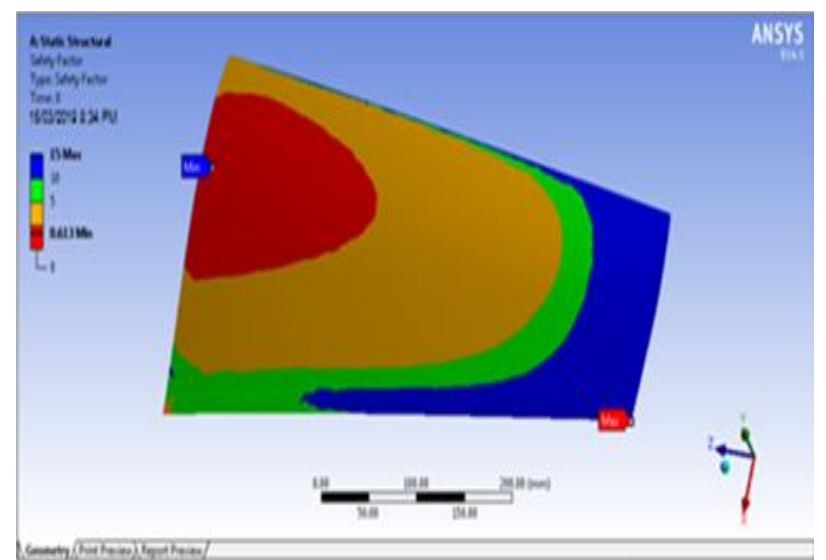

Figure 11:Safety factor of S2 GLASS at pressure load 30kPa, it shows the max value of Safety factor is 0.613.

\subsubsection{Fatigue Analysis With Kelvar49.}

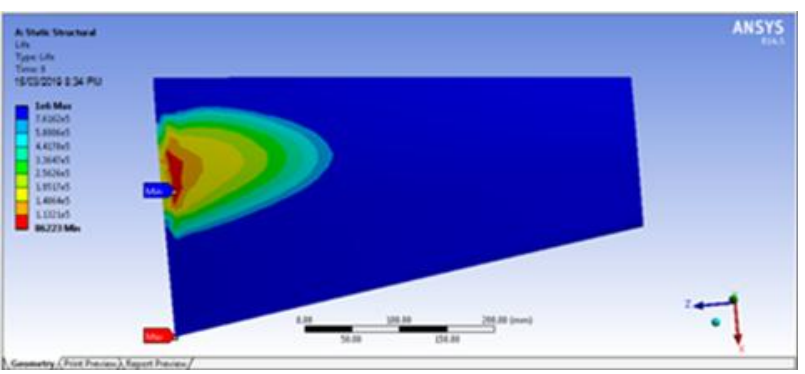

Figure 12: Life of KELVAR49 at pressure load $30 \mathrm{kPa}$, it shows the max value of Life is $1 \times \mathrm{e} 6$.

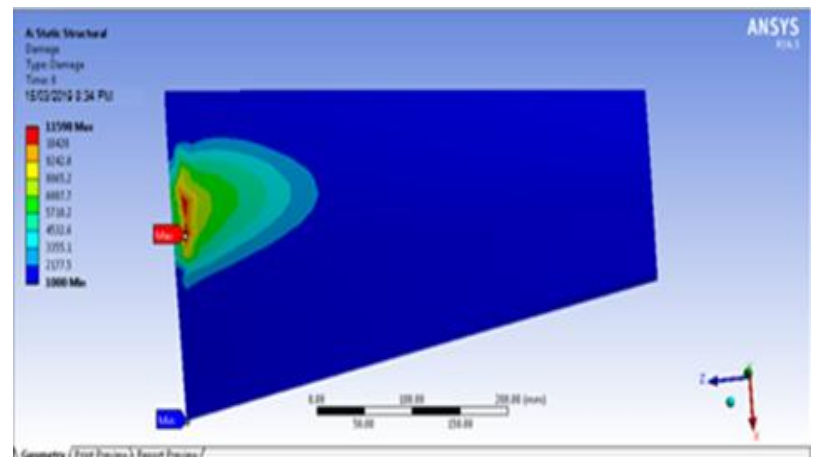

Figure 13: Damage of KELVAR49 at pressure load $30 \mathrm{kPa}$, it shows the max value of Damage is 11598.

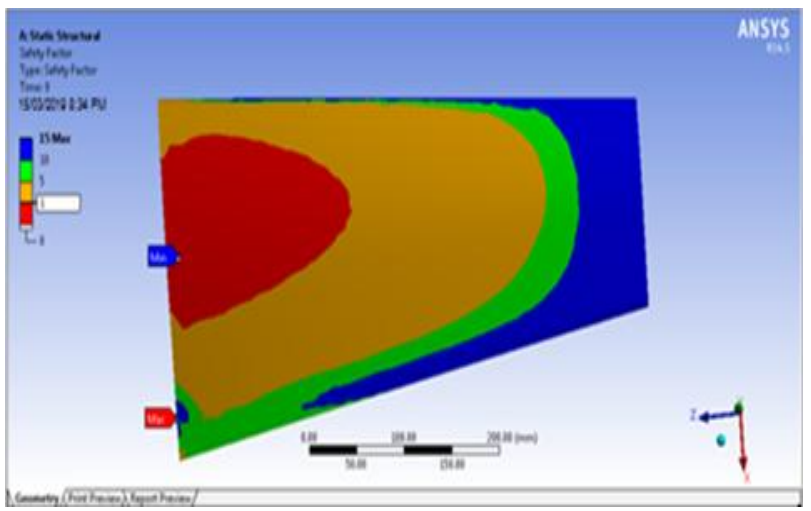

Figure 14:Safety factor of KELVAR49 at pressure load $30 \mathrm{kPa}$, it shows the max value of Safety factor is1.

\subsection{Fatigue Analysis Result Comparision}

The Table 3 shows the values of life, damage and Safety factor with S2 GLASS and KELVAR49

\begin{tabular}{|c|c|c|}
\hline MATERIAL & S2 GLASS & KELVAR49 \\
\hline Life & $1 \times \mathrm{e} 6$ & $1 \times \mathrm{e} 6$ \\
\hline Damage & 10714 & 11598 \\
\hline Safety factor & 0.613 & 1 \\
\hline
\end{tabular}

7.5 Modal Analysis.

\subsubsection{Modal Analysis of S2 Glass.}

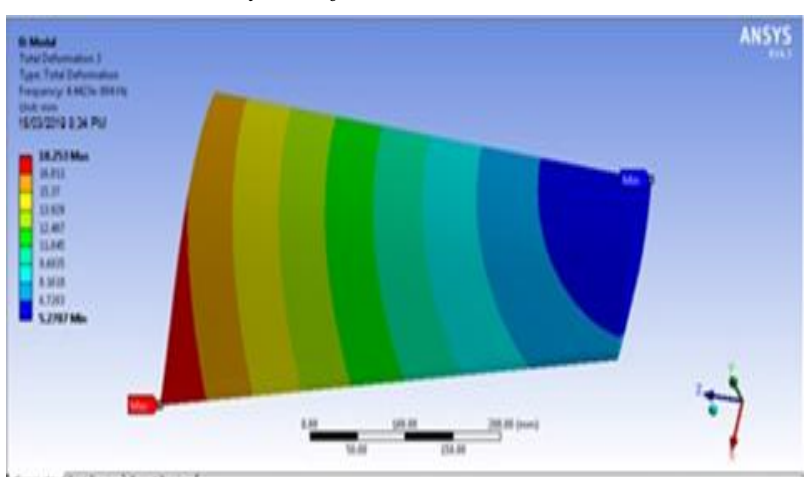

Figure15:Frequencies of S2 GLASS at pressure load $30 \mathrm{kPa} \&$ overall deformation $18.253 \mathrm{~mm}$, it shows the max price of frequencies is $4.4423 \mathrm{e}-004$.

7.5.2 Modal Analysis Of Kelvar49.

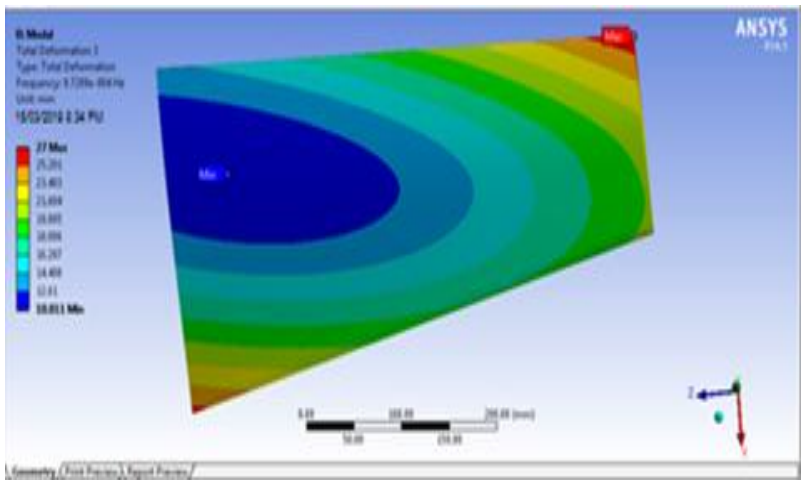

Figure16:Frequencies KELVAR49 at stress load $30 \mathrm{kPa} \&$ overall deformation $27 \mathrm{~mm}$, it suggests the max fee of frequencies is nine.7289e-004.

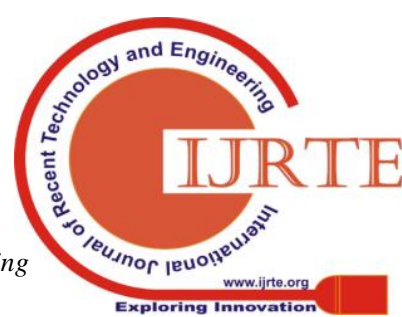




\subsection{Analysis Results Comparision.}

\begin{tabular}{|c|l|c|c|}
\hline \multirow{2}{*}{$\begin{array}{c}\text { TYPE OF } \\
\text { ANALYSIS }\end{array}$} & \multirow{2}{*}{$\begin{array}{c}\text { DETERMINED } \\
\text { PARAMETERS }\end{array}$} & $\begin{array}{c}\text { S2 } \\
\text { GLASS }\end{array}$ & $\begin{array}{c}\text { KELVAR } \\
\mathbf{4 9}\end{array}$ \\
\cline { 3 - 4 } $\begin{array}{c}\text { Static } \\
\text { Analysis }\end{array}$ & Deformation & 0.057516 & 0.040035 \\
\cline { 2 - 4 } & Stress & 1.4062 & 1.4369 \\
\cline { 2 - 4 } & Strain & $1.5154 \mathrm{e}-5$ & $1.1007 \mathrm{e}-5$ \\
\hline \multirow{2}{*}{$\begin{array}{c}\text { Fatigue } \\
\text { Analysis }\end{array}$} & Life & $1 \times \mathrm{e} 6$ & $1 \times \mathrm{e} 6$ \\
\cline { 2 - 4 } & Damage & 10714 & 11598 \\
\cline { 2 - 4 } & Safety factor & 0.613 & 1 \\
\hline \multirow{2}{*}{$\begin{array}{c}\text { Modal } \\
\text { Analysis }\end{array}$} & Deformation & 18.253 & 27 \\
\cline { 2 - 4 } & Frequencies & $4.4423 \mathrm{e}-$ & $9.7289 \mathrm{e}-$ \\
& & 004 & 004 \\
\hline
\end{tabular}

\section{VII.CONCLUSIONS}

The substances carried out for flying gadget wings are for the maximum aspect metal compounds. in this concept, the materials are supplanted thru composite substances like $S$ Glass and Kevlar 49.

Tapered Air region of knowledge wing showing is carried out on CATIA.

these three evaluation Static Structural investigation, Fatigue exam and Modal investigation all are is done in ANSYS.

Static Structural investigation is finished to determined the twisting, stresses, strains delivered with the useful resource of making use of masses.

Fatigue examination to gauge the lifestyles, harm and safety aspect of the wing.

Modeling exam to evaluate the frequencies concerning overall distortion.

So it very well may be finished up the $\mathrm{S} 2$ glass fabric is better cloth for flying device wing.

\section{REFERENCES}

1. design and Structural evaluation of the Ribs and Spars of Swept again Wing Mohamed Hamdan A1 ,Nithiyakalyani S2

2. Structural shape of a uav wing utilising confined factor technique farrukhmazhar

3. layout and analysis of Wing of a Ultralight aircraft Yuvaraj S R 1, Subramanyam P 2

4. Optimization of air deliver wing with composite cloth shabeer kp1 ,murtaza $\mathrm{m}$ a2

5. design and Finite detail evaluation of plane Wing using Ribs and Spars Guguloth Kavya

6. Static and dynamic research of a mean plane wing structure using mscnastrant.S.Vinoth kumar1, a.Waseem basha2, m.Pavithra3, v.Srilekha4.

7. Graeme J. Kennedy and Joaquim R. R. A. Martinsy, "A assessment of metallic and Composite plane Wings the use of Aerostructural design Optimization", college of Toronto Institute for Aerospace studies, Toronto, ON, Canada.

8. Peter J Rohl, Dimitri N Mavris and Daniel P Schrage, "Joined air dynamic and Structural Optimization of a rapid commonplace automobile Wing", college of Aerospace Engineering, Georgia Institute of generation Atlanta

9. Boyan Liu, " level development methodology for wing configuration problem to fine and clasping requirements", university of Florida

10. Kong, h. Park, y. Kim and ok. Kang "basic plan on wing of a piece scale wig vehicle with carbon/epoxy and froth sandwich composite form", sixteenth international collecting on composite substances.

11. F. H. Darwisha, G. M. Atmeh and Z. F. Hasan "Plan investigation and demonstrating of preferred flying system", Jordan magazine of Mechanical and business Engineering quantity 6, quantity 2, pp 183-191, 2012.

12. LeventÜnlusoy "Auxiliary plan and studies of the undertaking flexible wings of an unmanned aeronautical automobile", A postulation submitted to center East Technical college, Febuary 2010. 